\title{
CONSIDERACIONES SOBRE «FERRANDO SPAGNUOLO» Y OTROS MAESTROS IBÉRICOS *
}

\author{
POR \\ ADELE CONDORELLI \\ Instituto della Enciclopedia Italiana, Treccani. Roma
}

\begin{abstract}
The review of the two exhibitions on the Hernandos held at Valencia and, on a minor scale, in Florence, sheds a special light on the noteworthy contribution given by the two spanish painters to the dissemination of the oil painting technique in Florentine circles at the end of the 15th Century; mention is made of how Yañez drew inspiration from a drawing by Pollaiolo in conceiving the scene of the Baptist's Decollation. As for the Florence exhibition, the review rejects the attribution to Yañez of a part of Pecori's Circumcision. The problem of the Master of Bolea, with regard to Atri's paintings, is raised once again with specific references to drawings of Perugino for the Nativity and of Pollaiolo for the Flagellation.
\end{abstract}

La Exposición valenciana de los Hernandos, organizada por Fernando Benito, ha producido a cuantos han tenido ocasión de visitarla la emoción extraordinaria e inolvidable de poder finalmente admirar de cerca, y perfectamente restaurados, los doce paneles que componen las puertas del gran retablo de la catedral de Valencia. Recuerdo con cuanta desesperación, en el pasado, estuve delante de estas pinturas que no era posible examinar de cerca y en las cuales se adivinaba la excepcional belleza de los colores bajo la espesa capa de suciedad que los obscurecía. Los conocía en sus mínimos detalles gracias a la única, monografía de 1953, de Felipe Garín Ortiz de Taranco ${ }^{1}$, sobre Yáñez de Almedina que incluye también la obra de Fernando de Llanos, además de la preciosa colección de documentos relativos a la actividad de los dos pintores, pero, desgraciadamente, de las ilustraciones del libro, en blanco y negro, no es posible evaluar plenamente la valiosa gama cromática que se despliega en las pinturas. El catálogo de la exposición de Valencia sobre los Hernandos ${ }^{2}$, confeccionado por Fernando Benito, adquiere, por tanto, un papel determinante para una atenta lectura del estilo de los dos pintores, tanto

* Solamente ahora, cuando mi artículo estaba ya en la imprenta, he tenido noticia del ensayo de Pedro Miguel Ibáñez Martínez, Dibujos y Grabados en el proceso creador de Fernando Yáñez, Archivo Español de Arte, 278, 1997, pp. 127-142. Excusándome con el autor por no haberle podido citarle en las notas, aprovecho la ocasión para precisar que mi atribución a Yáñez de las pinturas de Atri era sólo, como indicaba el título del artículo de 1966, Problema de pintura valenciana, una tímida hipótesis en la que me limitaba a poner en evidencia las afinidades formales entre estas pinturas italianas de Atri y las de Yáñez.

Me alegro de que nuestros estudios, realizados paralelamente, sin haber tenido noticia, uno del otro, nos hayan llevado a encontrar, aunque con alguna divergencia de interpretación, idénticas fuentes iconográficas de Yáñez. Es, por otra parte, sabido que las divergencias de opinión son lo que más estimula la investigación científica.

1 Garín Ortiz de Taranco, F. M.: Yáñez de la Almedina pintor español, Valencia, 1953 (1978).

2. Los Hernandos pintores hispanos del entorno de Leonardo, cat., Valencia, 1998. 
por la belleza de las imágenes, cuanto por el cuidado que ha sido llevada a cabo la investigación de las fuentes iconográficas en cada una de las obras.

La Exposición de los Hernandos montada en Casa Buonarroti de Florencia, aun siendo de proporciones muy reducidas respecto a la de Valencia, ilustra bien el estilo y la formación artística florentina de los dos pintores manchegos, suscitando una viva sorpresa en los que, por primera vez, se ponen en contacto directo con las obras de Fernando de Llanos y de Fernando Yáñez de Almedina, uno de los cuales, en 1505, con el nombre de «Fernando spagnuolo» y la calificación no sólo de «pintor», sino incluso de «compañero y ayudante», aparece en el libro de cuentas de Leonardo ${ }^{3}$ relativo a la ejecución de la célebre Batalla de Anghiari en la sala del Gran Consejo de Palazzo Vecchio de Florencia, pintura que desgraciadamente se deterioró, como expone Vasari ${ }^{4}$, por haber usado demasiado aceite al querer colorear el muro y que conocemos sólo a través de copias derivadas de los dibujos de Leonardo y de sus discípulos. Puesto que ignoramos a cuál de los dos «Ferrando» se refiere Leonardo y suponiendo la colaboración de ambos en dicha obra, acertadamente se ha dado a la Exposición florentina el título de «Ferrando spagnuolo e altri maestri iberici nell'Italia di Leonardo y di Michelangelo», para subrayar así el estrecho vínculo de los dos artistas con la ciudad de Florencia.

Supongo que Fernando Benito, cogiéndome de sorpresa, ha propuesto mi participación en el encuentro sobre «Ferrando spagnuolo» para rendir homenaje a la «estudiante italiana» - que siempre he seguido siendo- que desde 1956, fecha de mi primer año de especialización en Historia del Arte bajo la dirección de Mario Salmi, continúa a seguir el recorrido de aquellos artistas italianos que trajeron a la península Ibérica la novedad del primer Renacimiento, aportando el nuevo orden fundado sobre la base científica de la perspectiva, dejando entrever de esa manera horizontes más vastos en un mundo como el ibérico, todavía aferrado a las formas del gótico flamígero.

Fui iniciada en esta clase de estudios por Mario Salmi quien, en 1929, había recorrido toda España en busca los artistas italianos del Medioevo y del Renacimiento, recogiendo en sus famosos cuadernos, que le salían de todos los bolsillos, minuciosas y agudas observaciones que expuso a continuación, además de algunos artículos fundamentales, en un curso de lecciones que tuvo lugar en la Universidad de Florencia durante el año académico de 1934-1935 ${ }^{5}$. Por el hecho de que sabía castellano y tenía la posibilidad de permanecer durante largos períodos en España, el Maestro me sugirió que continuase recorriendo el camino que él mismo había iniciado, aconsejándome, sin embargo, avanzar con extrema prudencia y cautela porque, como él decía, y cito sus palabras: «Las relaciones internacionales son un campo vasto y difícil que puede conducir tal vez a afirmaciones temerarias. Es necesario, por tanto, aprender un método y formarse un sistema de estudio para afrontar estos temas tan delicados» ${ }^{6}$. Tuve buena cuenta de los preciosos consejos del Maestro quien, por lo demás, estaba siempre atento para frenar con firmeza el ímpetu juvenil que nos empujaba a proponer atribuciones arbitrarias, es decir, carentes de las bases históricas y documentales capaces de sostenerlas.

Llegué a Valencia tras las huellas del emiliano Paolo de San Leocadio y del napolitano Francesco Pagano ${ }^{7}$, los dos pintores que, en 1472, habían sido llevados a Valencia por el

3 Gaye, G.: Carteggio inedito di artisti dei secoli XIV, XV e XVI, Florencia, 1840, II, p. 89.

4 Vasari, G.: Le Vite, a cura di P. Bettarini e P. Barocchi, IV, Florencia, 1976, p. 33.

5 Salmi, M.: Gli influssi dell'arte italiana sull'arte penisola iberica nel Medioevo e nel Rinascimiento, dispense racolte da A. Parronchi, Università di Firenze 1934-1935.

${ }^{6}$ Id., ibid., p. 4

7 Condorelli, A.: Paolo da San Leocadio, in «Commentari», XIV, 1963, pp. 134-150; 246-253. 
cardenal Rodrigo de Borja para pintar los frescos de capilla mayor de la catedral, donde ahora está situado el gran retablo de los Herrandos y donde, desgraciadamente, de los frescos no queda traza alguna, como tampoco queda rastro de Francesco Pagano, ya nunca más mencionado en los documentos que se conservan en la catedral. Por lo demás, de los que se conservan relativos a la ejecución de los frescos se deduce que Francesco Pagano debía ser más anciano que su compañero Paolo y de salud precaria; es, por tanto, posible que muriese en Valencia sin poder regresar a Nápoles. Paolo, por su parte, se casó, tuvo diversos hijos y trabajó con éxito en Valencia durante casi treinta años, divulgando las nuevas formas del Renacimiento, revestidas de las de su cultura de carácter emiliano-ferrarense. La Virgen del Caballero de Montesa, el San Miguel de Orihuela o el Cristo muerto sostenido por ángeles, firmado Paulus, con el retrato de un caballero de Montesa pintado en el reverso de la tabla, son obras de altísima calidad que, además de ejercer un fuerte influjo en el ambiente artístico valenciano, todavía dominado por los Osona, hicieron surgir en los artistas jóvenes más dotados el deseo imperioso de llegar a Italia para poder estùdiar directamente las obras de los grandes maestros del Renacimiento. Nápoles, que entonces formaba parte de la Corona de Aragón, embebida de la misma cultura de la otra ribera del mar, no podía ofrecer novedades concretas en el campo del arte, sino, en el mejor de los casos, buenos encargos. Roma y Florencia eran, por tanto, las metas ambicionadas, los dos centros de cultura aptos para plasmar los jóvenes artistas españoles y satisfacer su ansia de conocer.

No sabemos en qué año Fernando de Llanos y Fernando Yáñez de la Almedina, nacidos quizás en el decenio comprendido entre 1465 y 1475, llegaron a Italia. Si fueron por mar, como se supone, provenientes de Valencia, desembarcaron en Civitavecchia, ya que ésta era la ruta habitual en la época del dominio político de los Borja, y es verosímil que se parasen en Roma donde, dede el 1492, era Papa Rodrigo de Borja con el nombre de Alejandro VI. Fue, sin embargo, en Florencia donde los dos Herrandos permanecieron más tiempo y cuán largo fue este tiempo no lo conocemos. Como es sabido, las cuentas de Leonardo, donde se menciona al Ferrando spagnuolo, son del año 1505 y al año siguiente los dos pintores se encontraban ya de regreso en Valencia donde ejecutan por cuenta de los reverendos señores del Capítulo Catedralicio el retablo de los santos médicos Cosme y Damián. Con esta obra, los canónigos habían querido poner a prueba la habilidad de los dos pintores antes de confiarles el encargo de pintar los doce panales de las puertas del retablo de plata de la catedral. Pero, además de pintar los paneles y decorar en azul y oro de ley las estatuas de madera, como se lee en los documentos, los Hernandos idearon ciertamente la soberbia composición arquitectónica de la puerta, exposición del más puro Renacimiento, ejemplar único en un ambiente donde la estructura gótica del retablo perdurará durante el primer tercio del siglo XVI ${ }^{8}$.

Cómo pintaban los Hernandos antes de su permanencia en Italia continúa siendo, por el momento, un misterio, ya que no han llegado hasta nosotros obras documentadas anteriores a 1506 y no es empresa fácil individualizarlas. El impacto con el ambiente artístico florentino debió revolucionar su estilo, especialmente el de Yáñez, más joven que Llanos y, por tanto, más permeable a las nuevas ideas. Ciertamente debían ser muy hábiles en la técnica de la pintura al óleo, todavía poco conocida en Florencia y que se estaba experimentando en los talleres de Pollaiolo y de Verrocchio. Es fácil, por tanto, suponer que, en Florencia, en el último decenio del Quatrocento, nuestros pintores, poseedores de un perfecto dominio de

8 El encargo de la puerta del retablo coincide con la marcha a Gandía del ya sexagenario Paolo de San Leocadio, quien se pone al servicio de la duquesa María Enríquez, viuda de Juan de Borja, segundogénito de Rodrigo. ¿Juiciosa retirada frente a las nuevas ideas aportadas por los Hernandos o deseo de una vida serena, no lejos de las hijas que habían ingresado en el convento de las clarisas de Gandía siguiendo a la duquesa su madrina? 
esta técnica, fueron acogidos con gran deferencia. Para los Hernandos, las puertas de todos los talleres se abrieron de par en par, a juzgar por el denso entrecruzado de influjos y por el vasto repertorio iconográfico, derivado de dibujos de los más célebres maestros florentinos, que traslucen sus obras. Debían haber adquirido una notable fama si, al final de su permanencia en Florencia, el «Ferrando spagnuolo», probablemente Fernando Llanos, tuvo el extraordinario privilegio de ser asumido por Leonardo como colaborador, junto con su más joven e inseparable compañero de trabajo, según una suposición ya firmemente enraizada. Los dos Hernandos, vueltos a la patria, quisieron perpetuar el recuerdo de la emocionante experiencia vivida junto al gran Maestro, reproduciendo personajes que ya habían pintado en la Batalla de Anghiari, siguiendo fielmente los modelos de Leonardo celosamente. En el Cristo con la Cruz (Fig. 1) de la colección Godia de Barcelona ${ }^{9}$, aparece el viejo soldado del gorro rojo, aquí en el papel de esbirro, del que se conserva un dibujo de Leonardo en el museo de Oxford (Fig. 3). En la pintura con el mismo tema, replica ampliada de la precedente (Fig. 2), presentado en 1988 a la subasta de Sotheby's de Nueva York, atribuido a Gian Francesco Maineri, se nota el añadido de un segundo bribón derivado de otro caballero de la Batalla de Anghiari (Fig. 4). El mismo personaje aparece en el panel de la Resurrección de la Catedral de Valencia, permitiendo este detalle atribuir esta pintura a Fernando Llanos ${ }^{10}$. Otra señal tangible de su asociación con Leonardo nos lo ofrece Yáñez cuando reproduce en el gran medallón que adorna la casulla de S. Antonio de Florencia del Museo de Valencia, un Cristo con la Cruz con los esbirros, obra perdida de Leonardo, de la cual tenemos solamente un dibujo con la cabeza del Nazareno que se conserva en Venecia, en la Galería de la Academia, y que es conocida a través de copias mediocres de sus discípulos. Casi parece que Yáñez, al pintar esta pequeña tabla devocional, haya querido perpetuar el recuerdo de los acontecimientos más destacados de su vida, representando dos santos que le eran muy queridos: S. Antonio, con el homenaje alusivo a Leonardo, al ser este santo protector de Florencia, la ciudad de su formación artística, y S. Vicente Ferrer, patrón de Valencia, su ciudad de elección, que le hizo famoso.

El taller de Leonardo no fue el único frecuentado por los dos pintores españoles. Los vínculos con Filippino Lippi, Lorenzo di Credi, Botticelli, Durero, Antonio Pollaiolo, han sido puestos en evidencia por Fernando Benito y sus colaboradores en el catálogo de la Exposición de Valencia.

A propósito de Pollaiolo, quisiera hacer notar que Yáñez, al idear la escena de la Degollación del Bautista (Fig. 6) en una pintura que en el catálogo español se considera obra de taller, mientras que hasta ahora ha sido siempre atribuida tanto a Llanos como a Yáñez ${ }^{11}$, ha tomado como modelo uno de los dibujos con escenas de la vida de S. Juan (Fig. 5) que Pollaiolo realizó para los bordados sobre lama de oro de los ornamentos sagrados de San Giovanni de Florencia, custodiados hoy en el Museo de la Obra del Duomo. Los personajes

\footnotetext{
9 Condorelli Mori, A.: Interpreti spagnoli del Rinascimiento italiano, I, Un dipinto ritrovato del «Ferrando Spagnuolo», in Studi di storia dell'arte sul Medioevo e il Rinascimiento nel centenario della nascita di Mario Salmi, Florencia, 1992, pp. 633-638.

${ }_{10}$ Condorelli, A.: Una nuova atribuzione a Fernando Llanos e un «ritrovato» Cristo portacroce di Paolo di San Leocadio, in Scritti in onore di Alessandro Maraboittini, Roma, 1997, pp. 103-110. El Cristo con la Cruz de Sotheby's, hasta 1956, cuando fue publicado en la página 137 del primer volumen sobre Leonardo da Vinci de la edición de De Agostini de Novara como obra de un anónimo pintor toscano de 1500, formaba parte de la colección romana de Giovanni Libani.

${ }^{11}$ Los Hernandos, cit., p. 128; Condorelli Mori, A.: Interpreti spagnoli, pp. 634-636; Sricchia Santoro, F.: Maestri iberici nell'Italia di Leonardo e Michelangelo, in Ferrando Spagnuolo e altri maestri iberici nell'Italia di Leonardo e Michelangelo, cat., Florencia, 1998, Valencia, 1998, pp. 181-195: 188.
} 

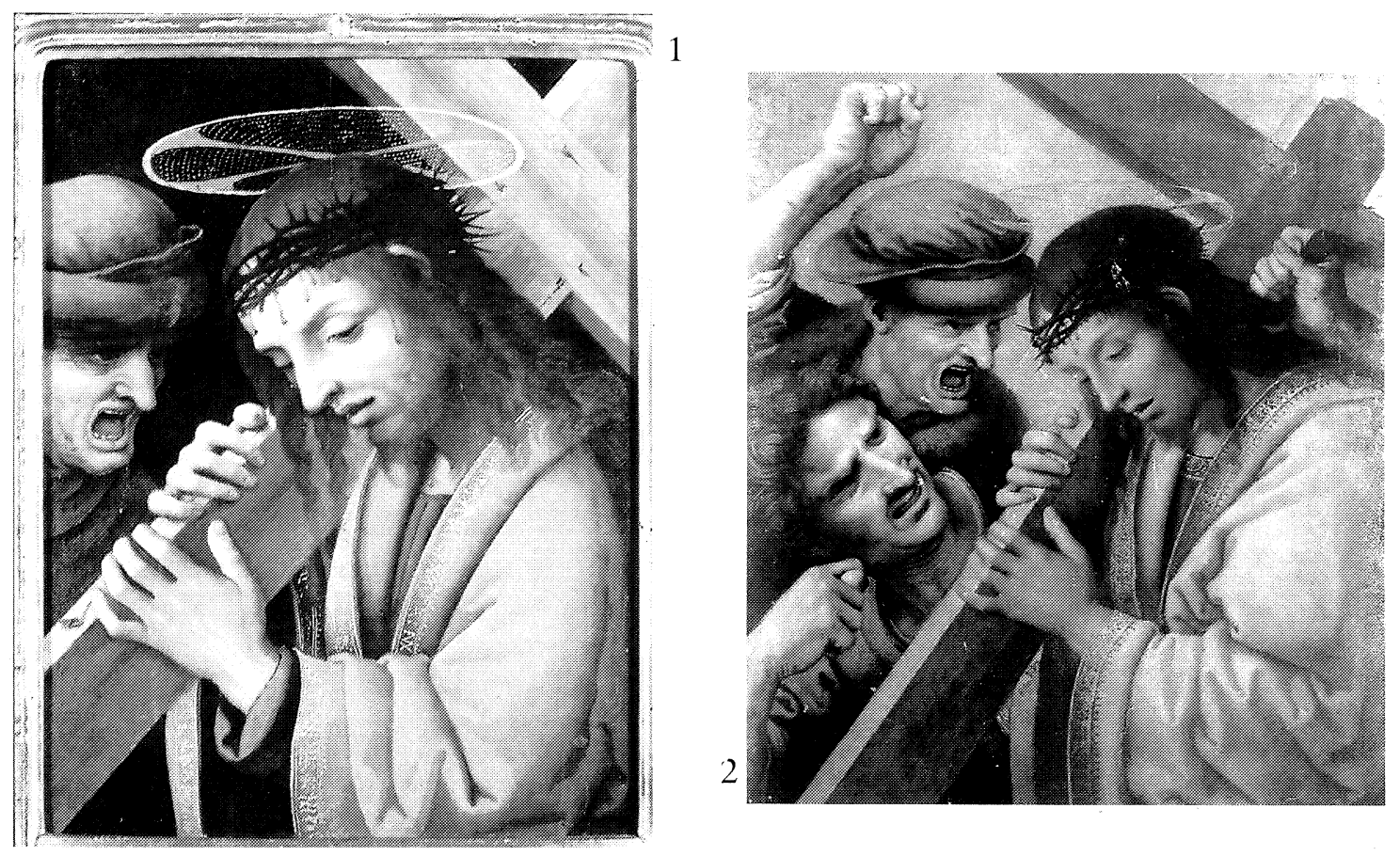

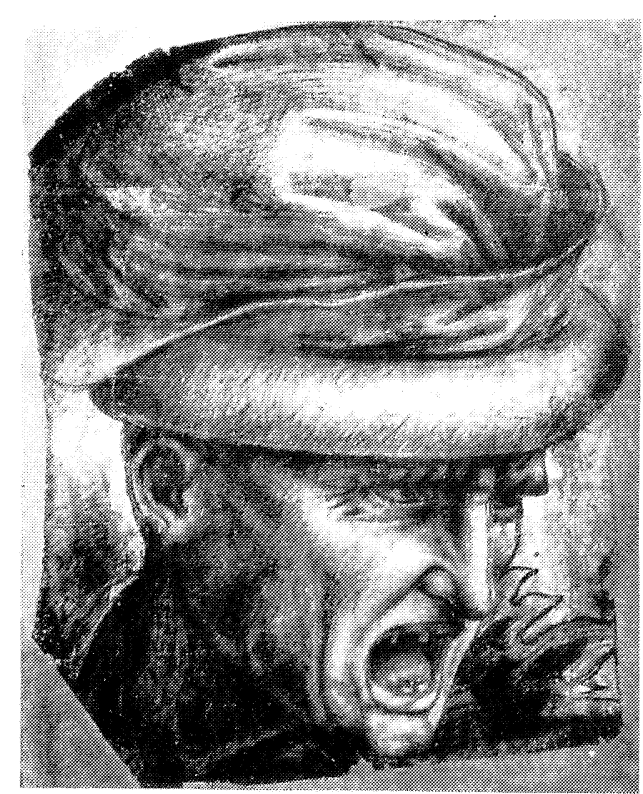

STUDIO PER LA BATTACLIA D ANCHARI

Oxford. Musee.
3

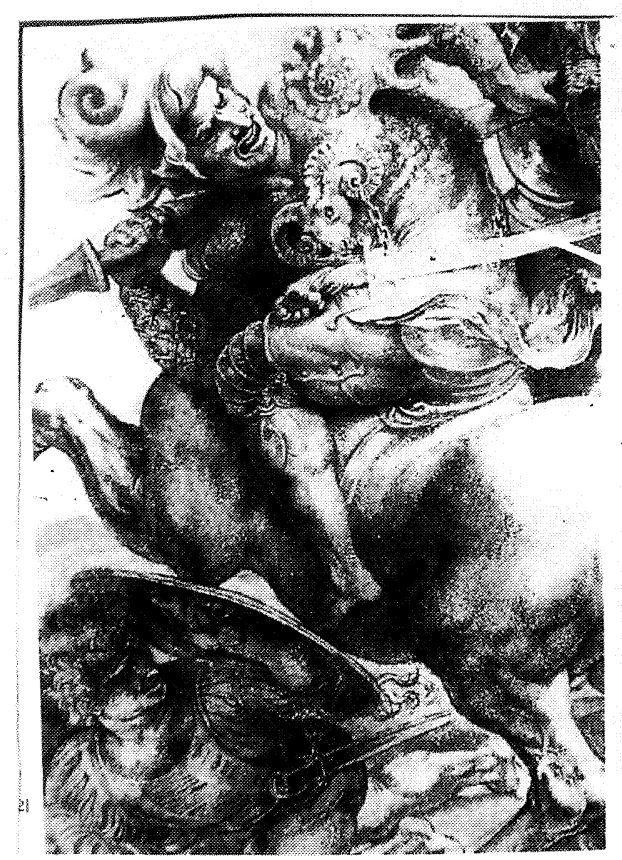

Figuras 1-4. «Ferrando spagnuolo»: Cristo con la Cruz. Barcelona, Colección Godia. Fernando de Llanos: Cristo con la Cruz. Antes en Nueva York, Sotheby's. Leonardo: Estudio para la Batalla de Anghiari. Oxford, Museum. Rubens: Dibujo para la Batalla de Anghiari (detalle). París, Louvre. 


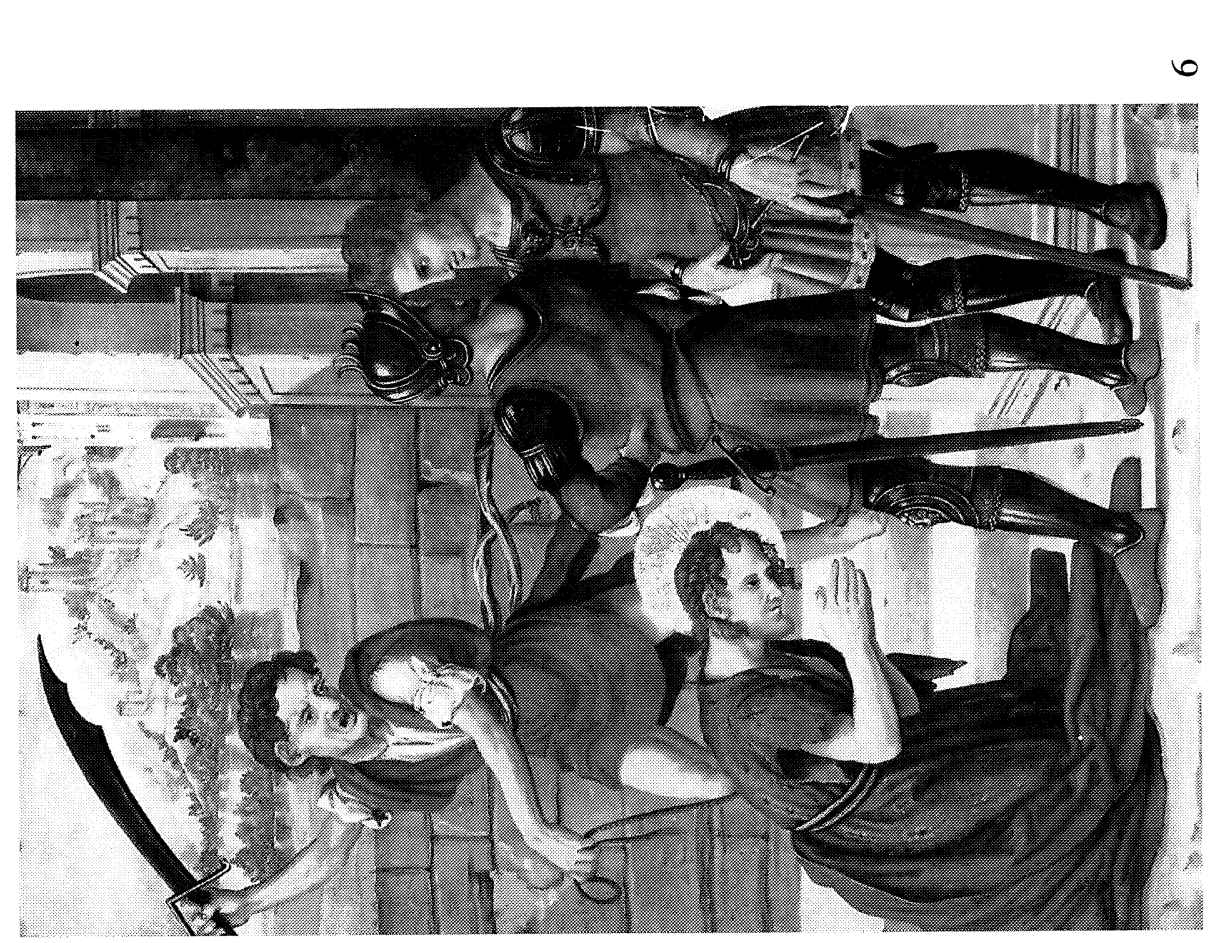

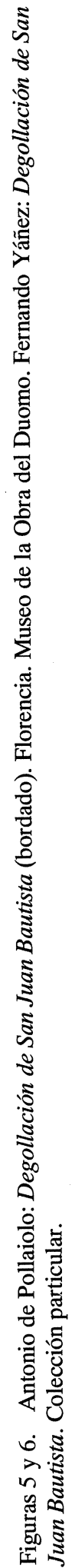




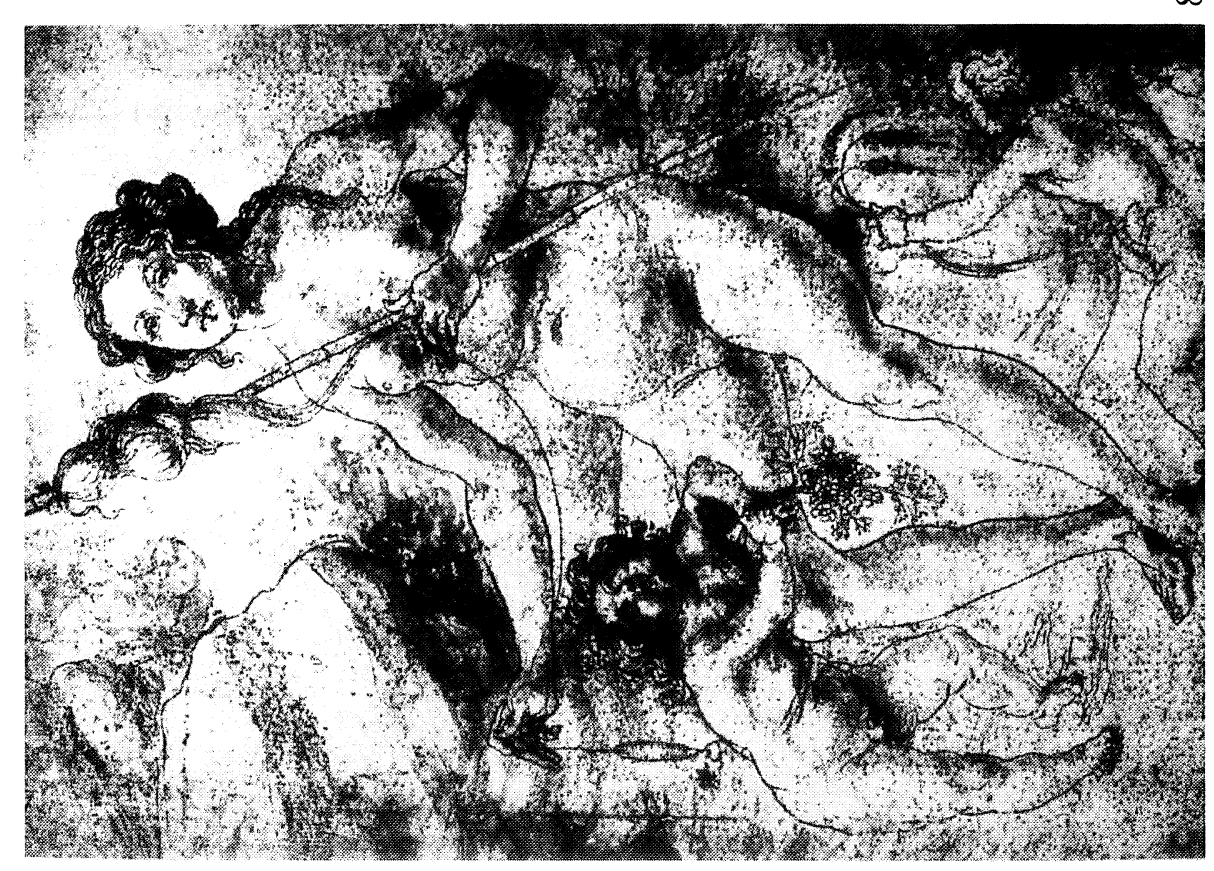

要

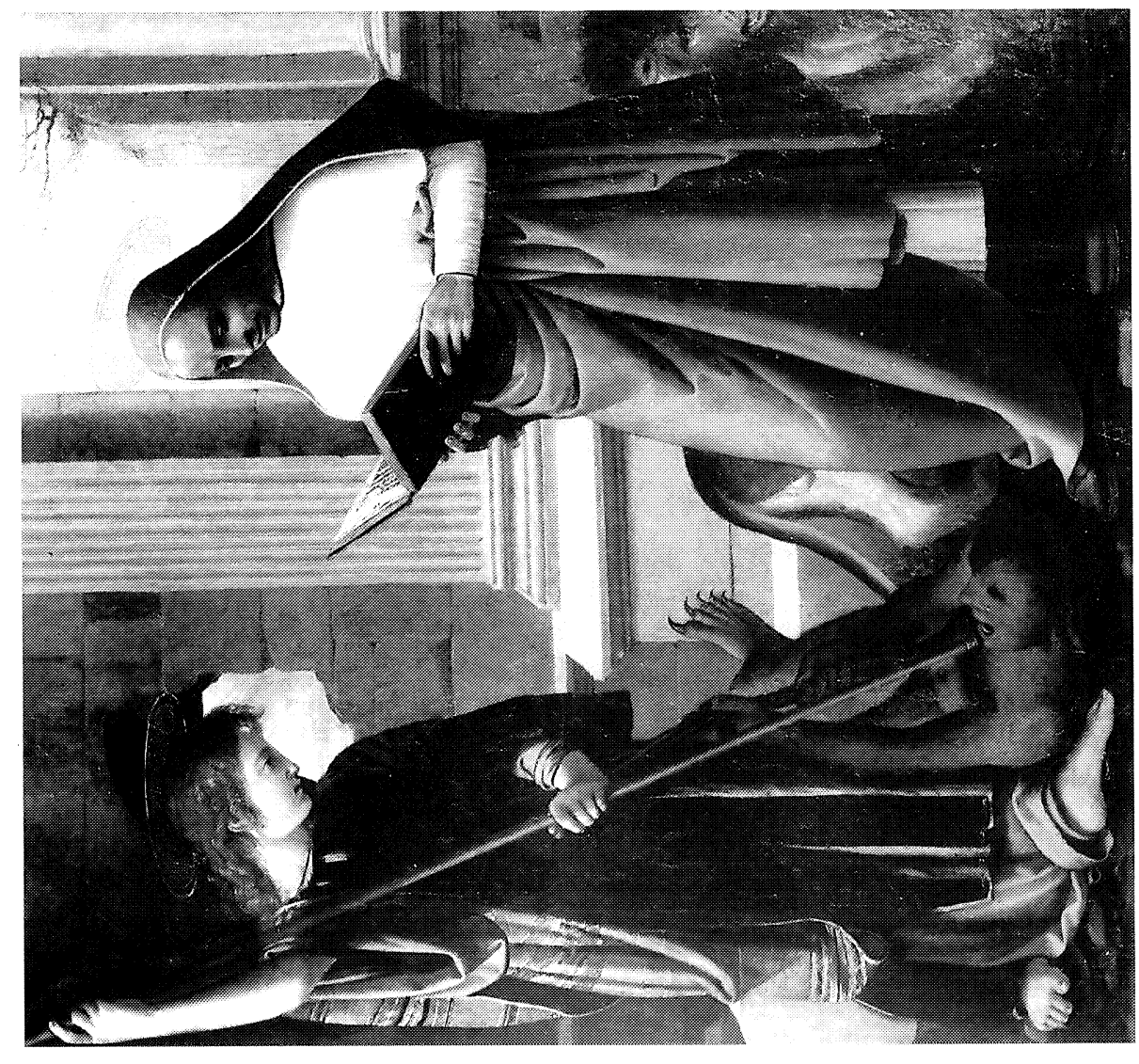

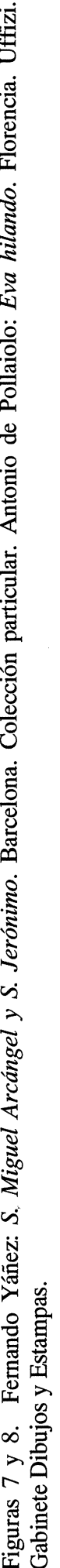



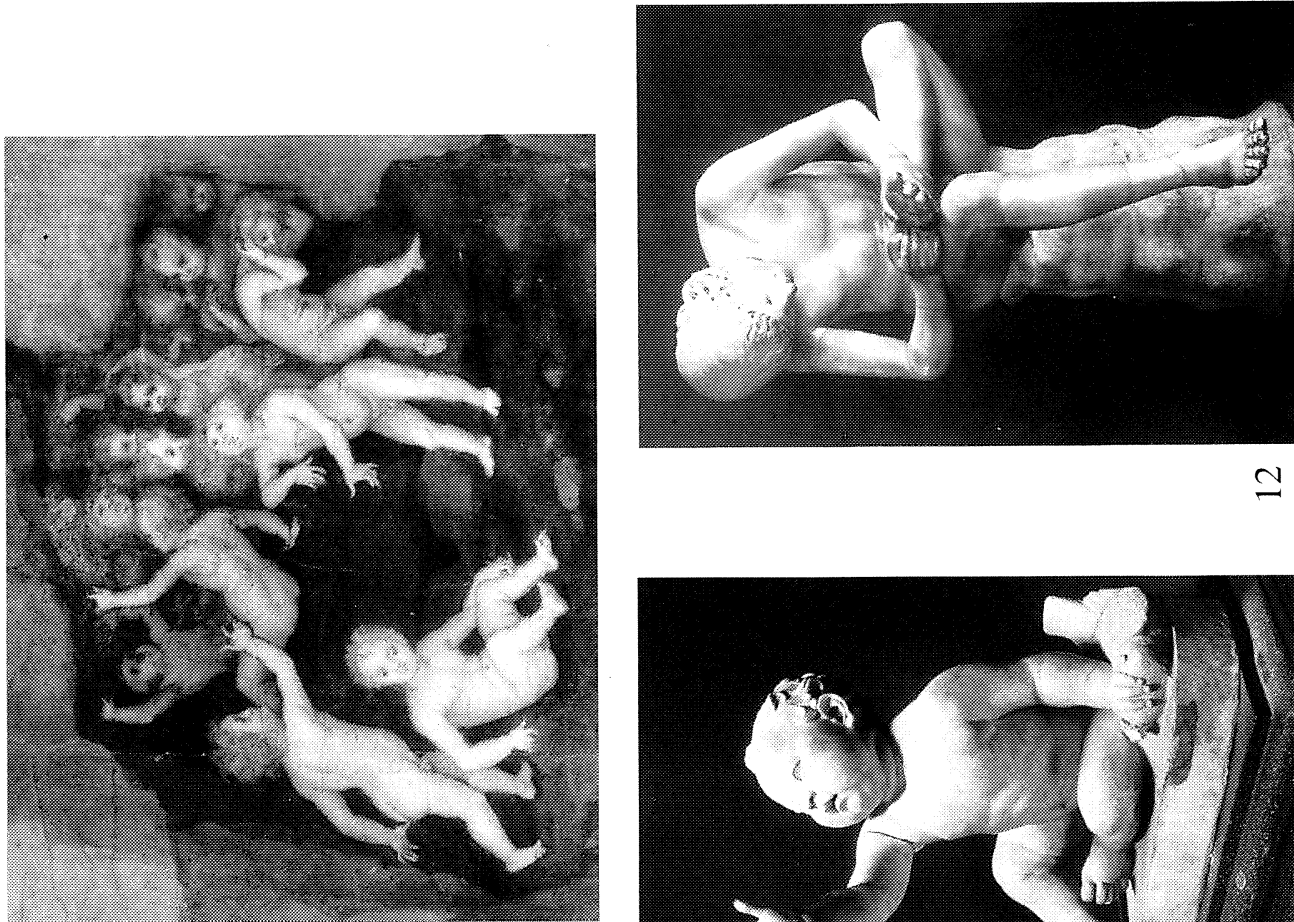

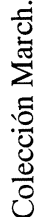

$\simeq$

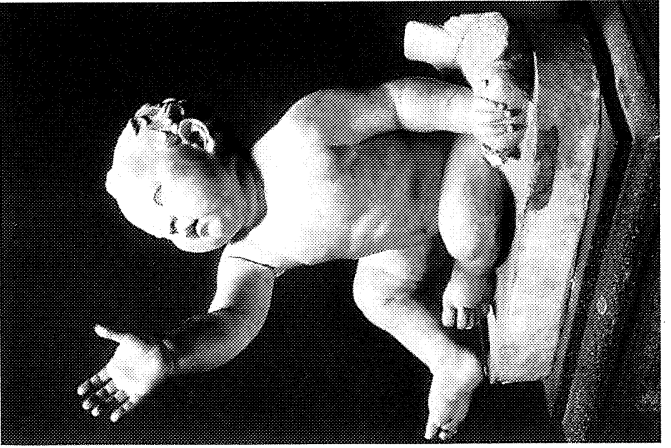

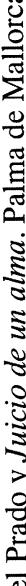
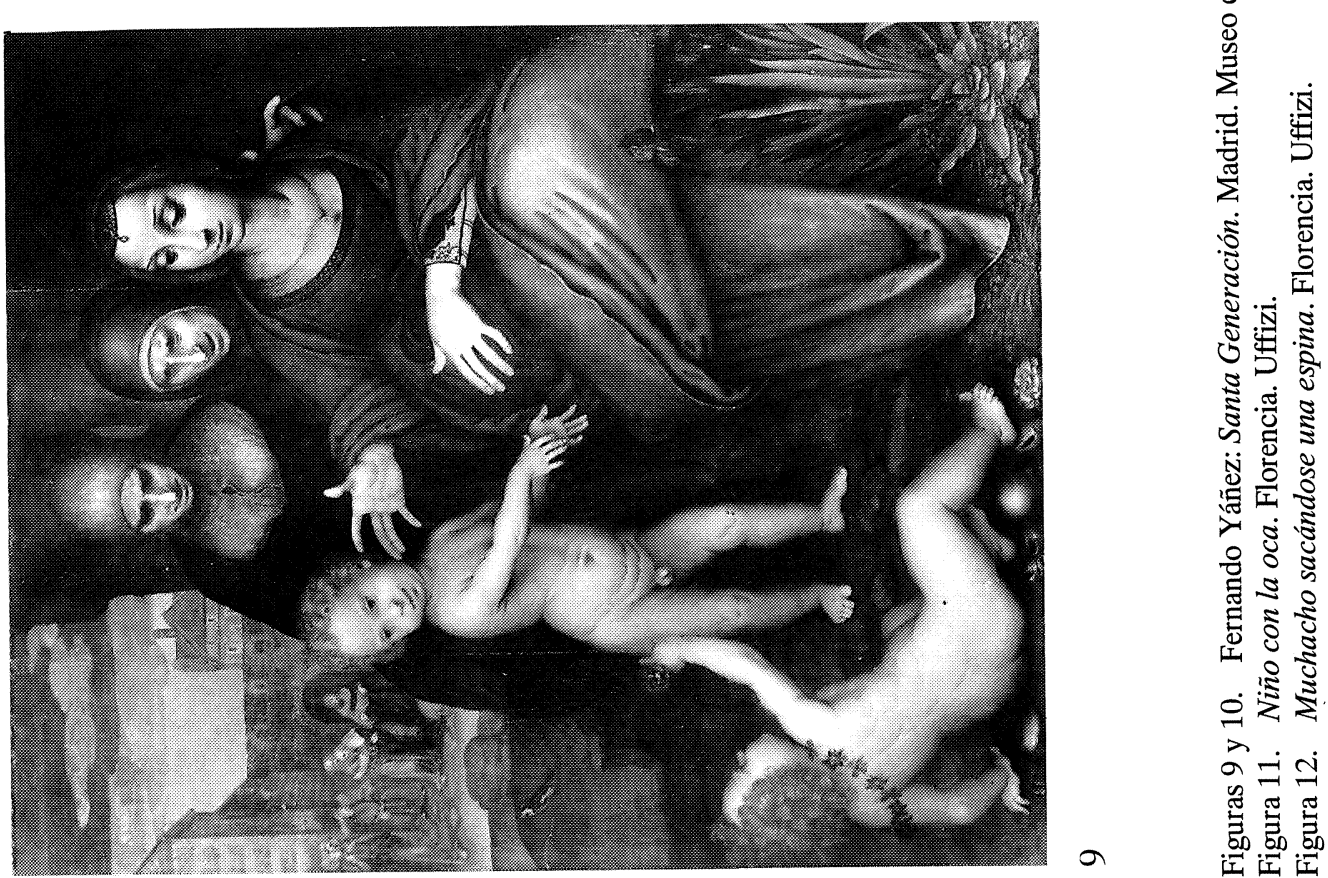
están colocados en el mismo espacio y de idéntico modo, aunque treinta años aproximadamente separen las dos obras. Por esta razón cambian las armaduras de los soldados, la arquitectura del fondo con la brecha en el muro antiguo, como en el San Miguel y San Jerónimo de Yáñez (Fig. 7), y no faltan las notas leonardescas como el paisaje que se difumina en una niebla azuleante, lo mismo que la máscara del verdugo.

Típico de Yáñez es el perfil del soldado que, a la derecha del cuadro, asiste al martirio del santo, el perfil griego clásico adoptado, además de por Leonardo, por aquellos artistas florentinos que tenían el privilegio de poder admirar y estudiar las «antigüallas» de Lorenzo de Médicis, entre las cuales se hallaba un camafeo grabado con la cabeza de Herakles (Fig. 18) cuabierta con la piel de león, actualmente en el Museo Nacional de Nápoles. Creo que ésta es la fuente de inspiración del modelo usado por muchos pintores de nuestro Renacimiento. Además, el tema recurrente del niño que, sentado en tierra, apoya su manecita en el suelo mientras tiende el otro brazo hacia lo alto, que encontramos en Pollaiolo cuando representa a Eva que hila (Fig. 8), en el San Juanito de la Virgen de las Rocas, de Leonardo, en la Santa Generación de El Prado (Fig. 9) y en el Juicio de la Colección March (Fig. 10), obra de Yáñez, tiene como arquetipo la estatuilla del niño con la oca (Fig. 11), una de las innumerables copias del original efesino, datable de la segunda mitad del siglo II después de Cristo, descrita por Vasari ${ }^{12}$ como perteneciente a la colección medicea, de la cual también formaba parte, siempre según Vasari, una réplica del muchacho «en el acto de sacarse una astilla del pie, semejante al del Capitolio», es decir, al famoso Niño de la espina (Fig. 12) que Yáñez representa en el encuentro en la Puerta Áurea, uno de los paneles del retablo de Valencia (Fig. 13).

El bagaje cultural acumulado, en el primer decenio de 1500, por los dos Hernandos es verdaderamente notable. Eran los años en que, en Florencia, Miguel Ángel rivalizaba con Leonardo en la decoración del Palazzo Vecchio, el joven Rafael habitaba allí, Lorenzo de Credi experimentaba la «tempera grasa» como se llamaba la mezcla de tempera y óleo, y fra Bartolomeo llevaba adelante esta técnica obteniendo brillantes efectos pictóricos, lúcidas trasparencias, inéditas en la pintura precedente, cualidades todas peculiares de la pintura de Yáñez. ¿Es demasiado osado, suponer que en la evolución de esta técnica deba verse la válida contribución de los Hernandos? Nos gusta imaginar que ellos formasen parte de aquellos jóvenes florentinos y forasteros que, como dice Vasari ${ }^{13}$, frecuentaban el taller de Baccio d'Agnolo «con los mejores y primeros artífices de nuestro arte, donde tenían lugar, especialmente en invierno, bellísimos discursos e importantes discusiones».

A la luz de cuanto hemos dicho hasta ahora, no nos es fácil aceptar la propuesta de que también Fernando Yáñez ${ }^{14}$ participó en la pintura que representa la Circuncisión, expuesta en la Exposición florentina (Fig. 14), obra de aretino Domenico Pecori y de Nicoló Soggi, con ayuda de «un pintor español que coloreaba bien al óleo, y ayudaba en esto a Domenico, que no tenía tanta práctica en colorear a óleo cuanto a tempera», como escribe Vasari en la vida de Don Bartolomeo della Gatta ${ }^{15}$. Este retablo robado y vandálicamente desmembrado en 1922, del cual, los varios fragmentos recuperados han sido reunidos y custodiados en el Museo de Arezzo, fue encargado a Peri el 15 de mayo de 1506. El primer pago hecho a Fernando de Llanos por el retablo de los Santos Médicos, en Valencia, se fecha el 8 de julio de

12 Vassari, G.: Le Vite. Anticaglie che sono netta sala del Palazzo Pitti, Bolonia, 1647, parte III, vol. II, p. 416.

13 ID., Le Vite, Baccio d'Agnolo, a cura di G. Milanesi, III, Florencia, 1889, p. 350.

14 Ferrando Spagnuolo, cit., pp. 208-213, con bibl.

15 Vassari, G.: Le Vite, a cura du G. Milanesi, III, Florencia, 1878, p. 222. L. Tramoyeres creía que el pintor español, ayudante de Pecori, era Eernando Llanos; ver ID., La capilla de los Jurados de Valencia, en «Archivo de Arte Valenciano», 1919, pp. 73-100. 

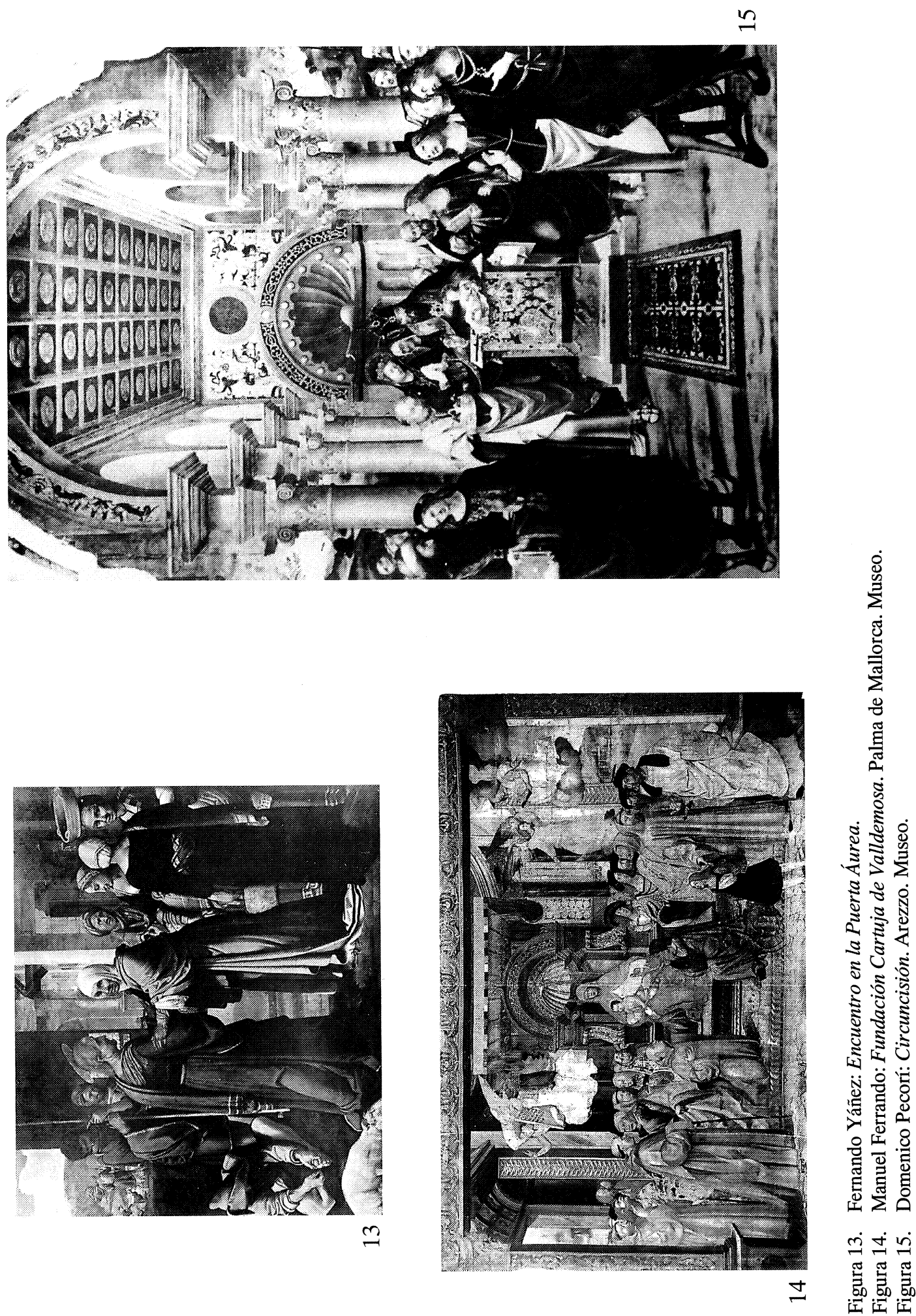

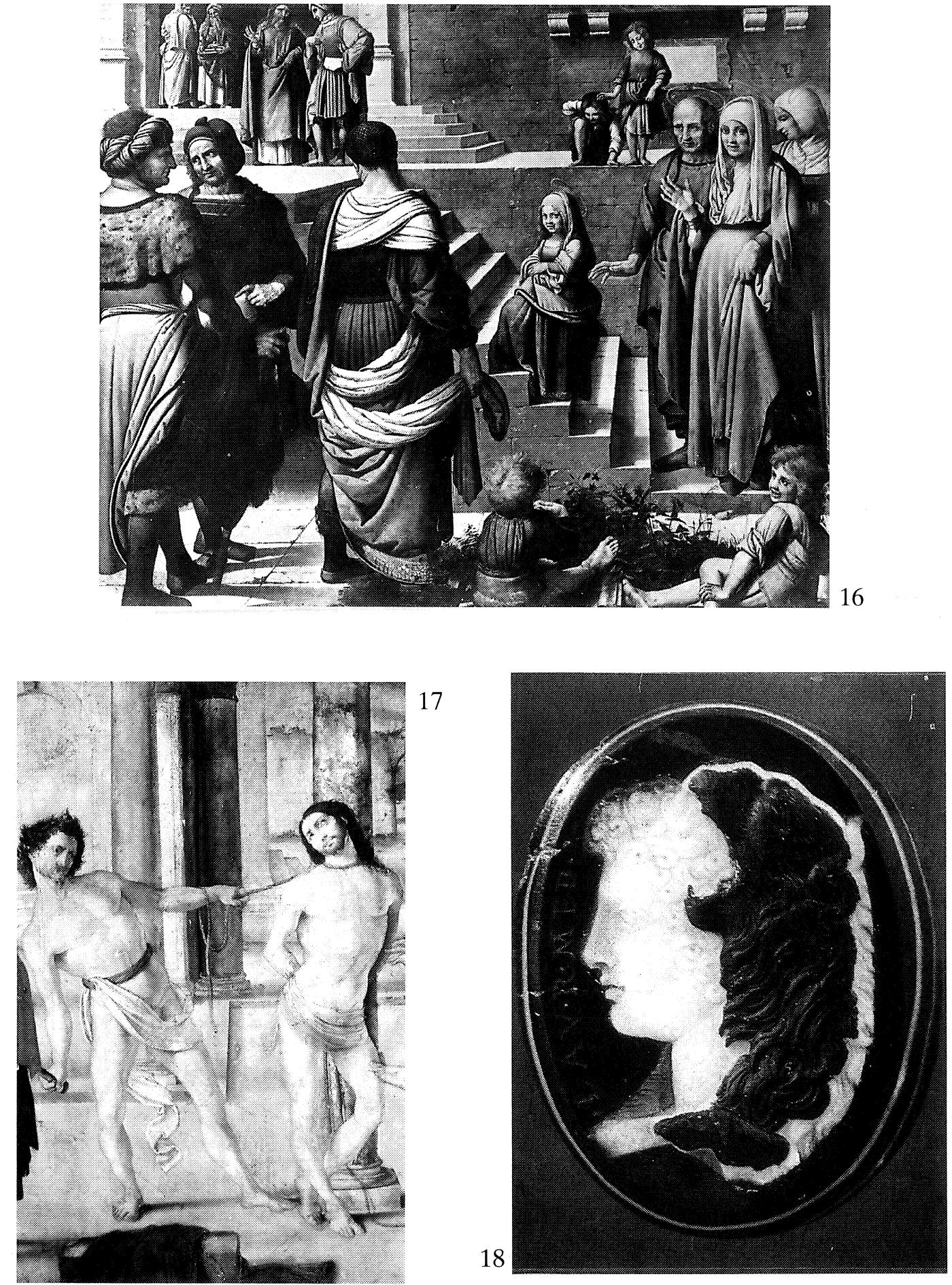

Figuras 16-18. Fernando Yáñez: Presentación de la Virgen en el Templo. Valencia. Catedral. Flagelación (detalle). Atri. Museo del Duomo. Herakles. Napóles. Museo Nacional. 

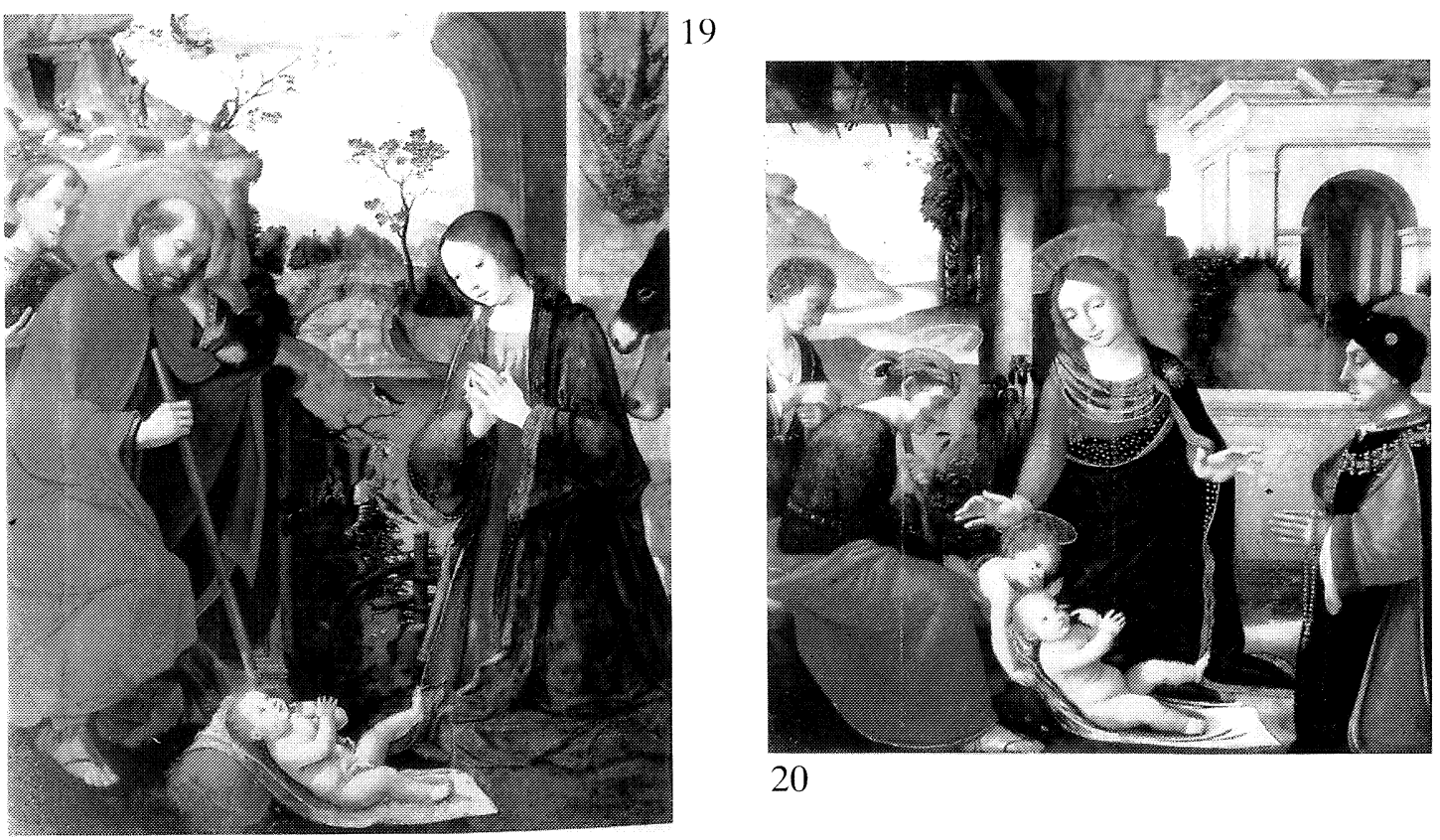

20
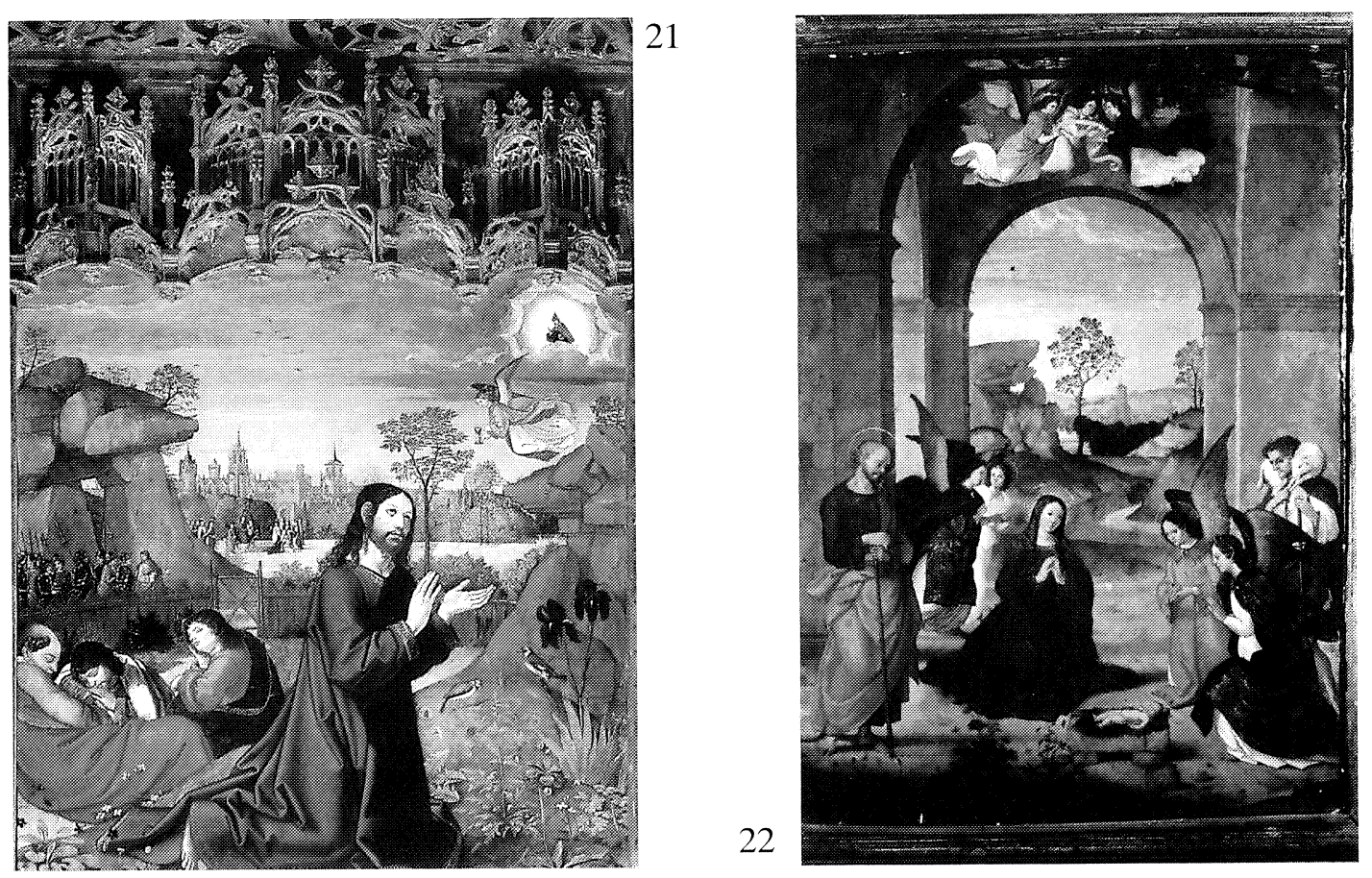

Figuras 19-22. Maestro de Bolea (?): Adoración del Niño. Siena. Pinacoteca. Fernando de Llanos: Adoración del Niño. Madrid. Colección particular. Maestro de Bolea: Oración del Huerto. Bolea. Colegiata. Natividad. Atri. Museo del Duomo. 
1506, y el 12 de septiembre del mismo año el nombre de Yáñez aparece junto al de Llanos en la segunda parte del pago. Se pretende que en este lapso de tiempo, Yáñez que habría acabado de dejar, imaginamos con cuánto sentimiento, el taller de Leonardo y los extraordinarios círculos culturales florentinos, habría corrido a Arezzo a ayudar a un pintor mediocre, como lo era Domenico Pecori, solicitado por Soggi, dejando que su compañero más anciano se aventurase solo en el largo y ciertamente no fácil viaje de regreso a Valencia. Semejante eventualidad no parece verosímil, tanto más que el retablo no se llevó a término hasta 1511. La hipotética estancia de Yáñez en Arezzo se habría limitado a pocos meses, durante los cuales habría pintado sólo la figura central del sacerdote y los dos personajes que están a su derecha. Ya Bertaux ${ }^{16}$ había supuesto que el colaborador de Domenico Pecori en Arezzo debía haber sido Manuel Ferrando, español y coevo de los Hernandos, con los cuales debió encontrarse en Toscana. Esta hipótesis, compartida por Suida y por Mayer ${ }^{17}$, fue minuciosamente controlada por el aretino Mario Salmi, quien, en 1929, se personó en Palma de Mallorca, en el Museo de la Lonja, para examinar de visu la gran pintura de Manuel Ferrando que celebra la fundación que la Cartuja de Valldemosa. De este examen, la opinión de que el ayudante de Domenico Pecori había sido realmente Manuel Ferrando salió reforzada. La pintura mallorquina muestra grandes vínculos con el Renacimiento italiano, especialmente por los elementos arquitectónicos decorados de nichos, como los que vemos en obras de Melozzo o de Pinturicchio. El ángel de la izquierda de formas amplias y un poco groseras de Signorelli, como lo definía Mario Salmi, recuerda el personaje de la cabellera suelta que sostiene un libro, a la derecha de la Circuncisión, también éste de impronta signorelliana. Finalmente, idéntico es en las dos pinturas el motivo decorativo del arco que encierra el nicho en forma de concha. A propósito de la pintura de Mallorca, Mario Salmi la define «producto de un coacervo cultural hispanoflamenco e Italia central». Y añade: «al tener contactos ciertos con el ambiente de Pecori, podemos concluir que el pintor español colaborador del aretino es verdaderamente Manuel Ferrando» ${ }^{18}$. Esta atribución, aceptada sin reservas por Post ${ }^{19}$ y por Angulo Íñiguez ${ }^{20}$, parece aún hoy la más plausible.

En la Exposición florentina, entre los maestros ibéricos que, en los mismos años que los Hernandos, residían en Italia, figura el Maestro de Bolea con una Adoración del Niño ${ }^{21}$, proveniente de la Pinacoteca de Siena. El influjo de Lorenzo de Credi en la iconografía del Niño parece evidente, como lo es en el Niño de la Adoración con donante de Fernando de Llanos (Fig. 19 y 20), mientras que el paisaje es de inspiración umbra, según los cánones de Perugino. La única nota de estilo flamenco es la mata de rosas con jilgueros que aproxima esta pintura a una de las tablas del retablo de Bolea en la que se representa la Oración en el huerto (Fig. 21), donde aparece en el fondo de la misma formación rocosa que vemos tanto en la Adoración del Niño de Siena, cuanto en la Natividad de Atri; pero este motivo iconográfico desde hacía tiempo había sido ya divulgado en Castilla por Juan de Borgoña.

En el mismo catálogo, al Maestro de Bolea se le asignan las dos tablas con la Natividad y la Flagelación (Figs. 22-25), conservadas en el Museo del Duomo de Atri ${ }^{22}$, dando crédito

16 Bertaux, E., en Michel, A.: Histoire de l'Art, IV, 2 partie, Paris, 1911, p. 915.

17 Suida,.W.: Leonardo und sein Kreis, München, 1929, p. 250 y ss.; Mayer, A. L.: Historia de la pintura española, Madrid, 1928, p. 125.

${ }_{18}$ Salmi, M.: Contributi aretini alla storia dell'arte, II, Manuel Ferrando, en «Atti e memorie dell'Accademia Petrarca di Lettere, Arti e Scienze», XXX-XXXI, 1941, pp. 78-88.

${ }_{19}$ Post, C. R.: A History of Spanish Painting, XI, Cambridge (Mass.), 1953, p. 177.

20 Angulo Íñiguez, D.: Pintura del Renacimiento, Madrid, 1954, p. 41.

21 Ferrando Spagnuolo, cit., pp. 192-193.

22 Sricchia Santoro, F.: ibid., pp. 192-193. 


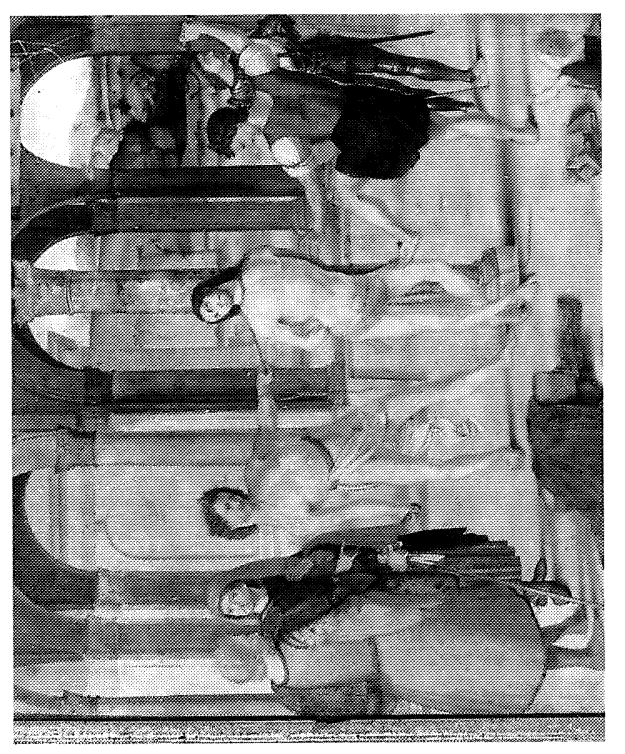

オ

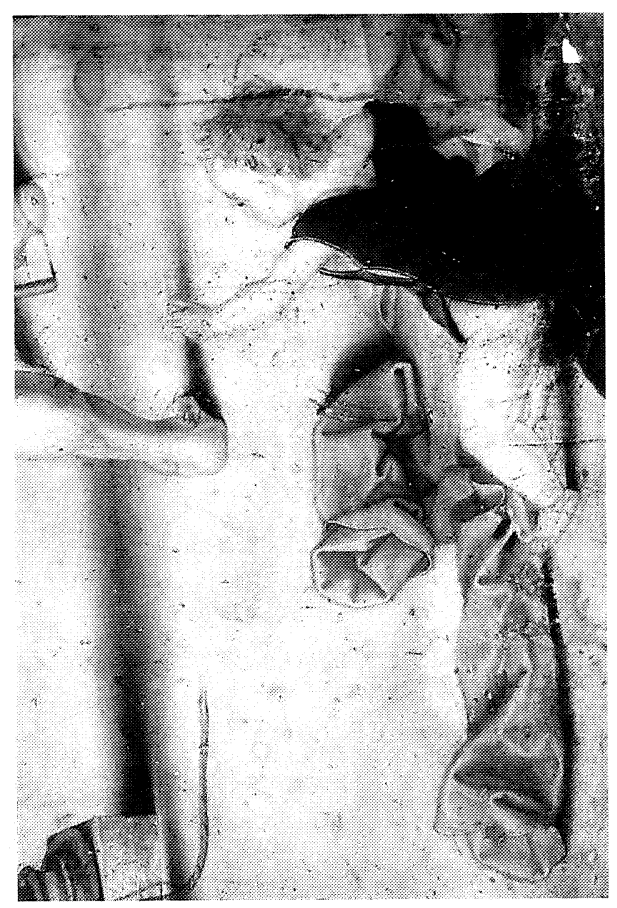

๙

ก

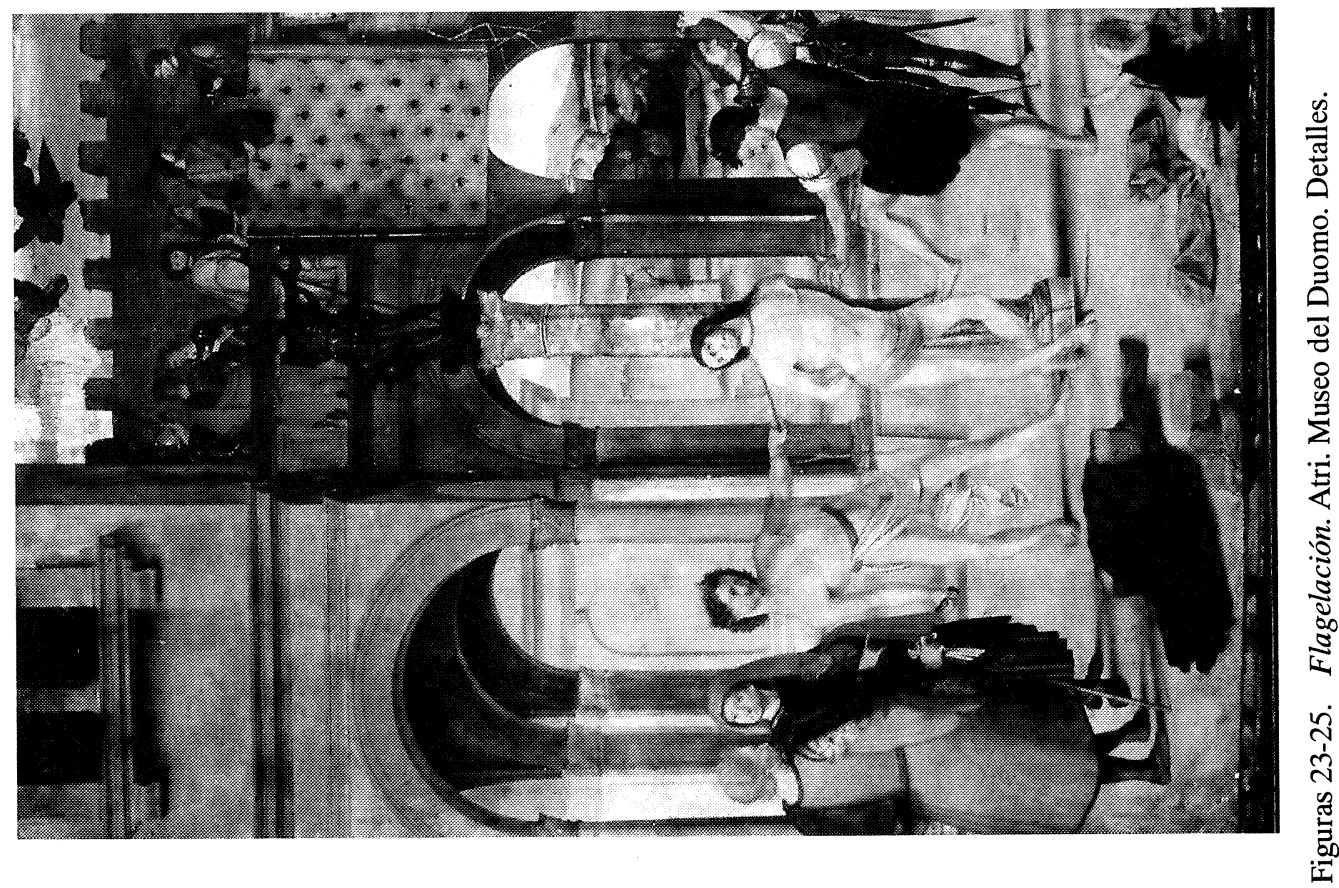



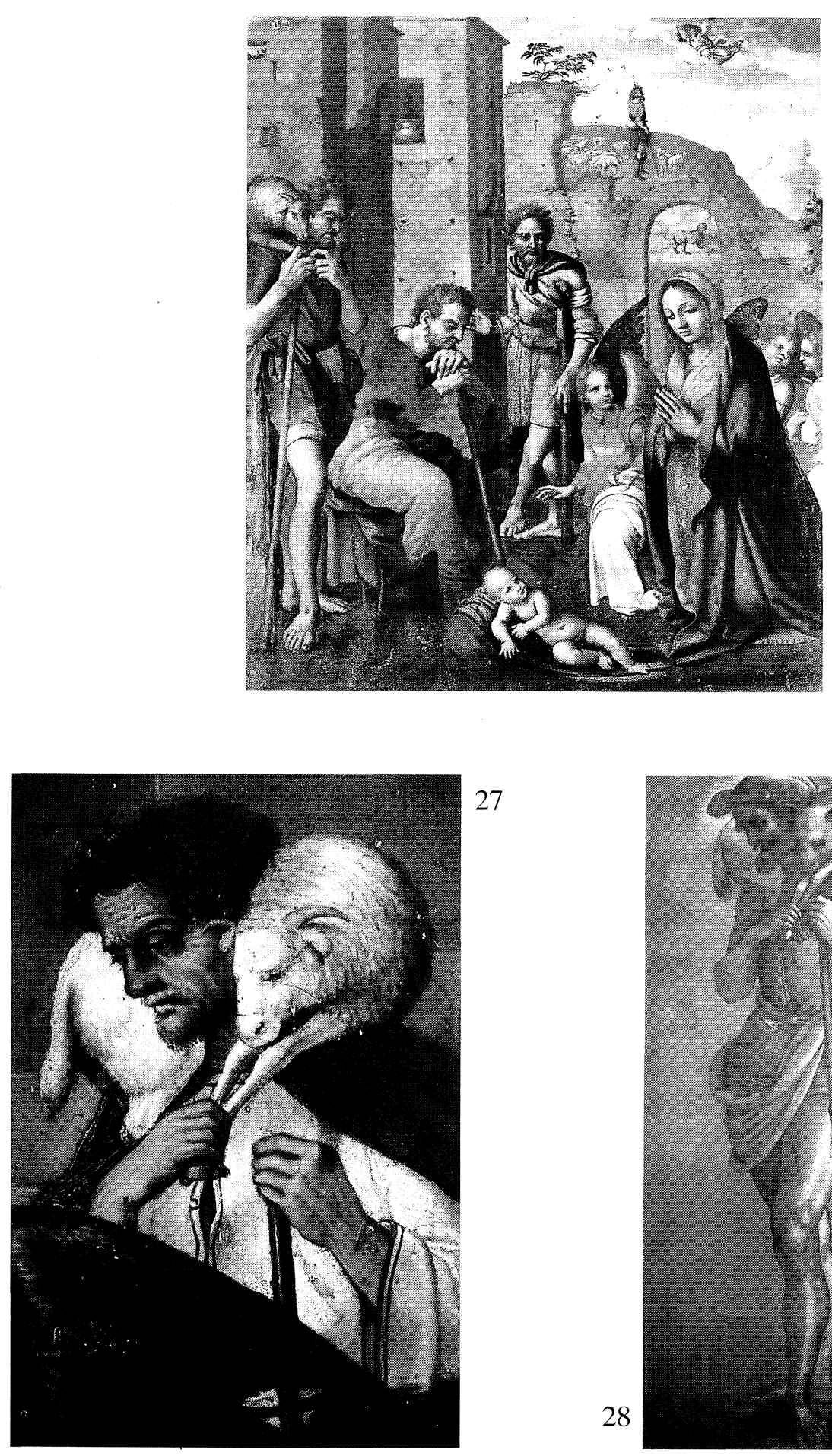

27

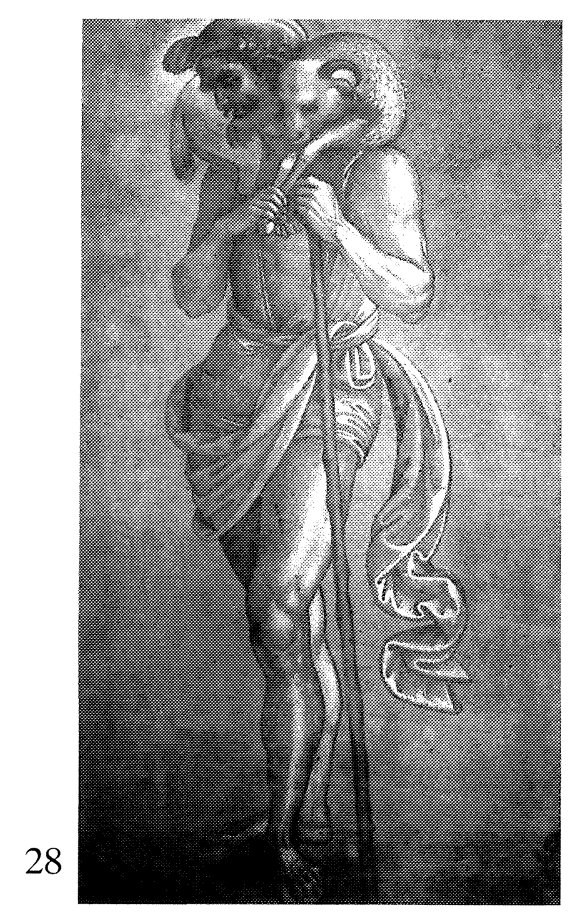

Figuras 26-28. Fernando de Llanos: Adoración de los pastores. Murcia. Museo Diocesano. Natividad. Detalle. Atri. Museo del Duomo. Pevugino: Pastor. Florencia. Uffizi. Gabine de Dibujos y Estampas (n. ${ }^{113}$ ). 
a la atribución ya propuesta por Angulo Íñiguez ${ }^{23}$, quien avanzaba el nombre de Pedro de Aponte, erróneamente considerado, en aquel tiempo, autor del retablo de Bolea. Los vínculos de estas pinturas con el mundo de los Hernandos son indudables ${ }^{24}$. Basta observar en la Natividad al pastor con el corderito al cuello (Fig. 27) que aparece tanto en el fondo de la Santa Generación de Yáñez (Fig. 9), cuanto en la Adoración de los pastores de Llanos (Fig. 26). Entrambos, para representar al pastor se valieron, usándolo al revés, de un dibujo atribuido a Perugino, conservado en Florencia, en el Gabinete de Dibujos y Estampas de la Galería de los Uffizi (Fig. 28). En la Flagelación encontramos de nuevo al Niño que, sentado en tierra, tiende el brazo, el muro almenado de mampostería, alternancia de piedra y ladrillo según el uso ibérico, visible en la Santa Generación (Fig. 9), y los dos espectadores de la izquierda que, en idéntica pose, encontramos en la Presentación de la Virgen en el templo, de Valencia (Fig. 16). Pero la escena central deriva toda entera de Pollaiolo. De la batalla de los desnudos provienen los dos flagelantes, y el Cristo en la columna, en la expresión del rostro, la torsión del busto y la posición de las piernas, está claramente inspirado en otro dibujo de Pollaiolo que representa a Adán. Las pinturas de Atri, lo mismo que la Adoración del Niño de Siena, aparecen en verdad como de calidad superior y de cultura más avanzada que las del retablo de Bolea, conservado en la colegiata-fortaleza del pequeño pueblo de este nombre, aferrado a una pendiente rocosa que se yergue solitaria en la vasta llanura aragonesa.

El Maestro que, probablemente en el último decenio del siglo XV, concibió el gran retablo, obra de muchas manos, según la costumbre española, parece provenir del círculo castellano de Juan de Borgoña.

El complejo problema del Maestro de Bolea continúa todavía sin resolver y debe ser tratado con mucha cautela. Es mérito de la Exposición florentina el haberlo planteado, poniéndolo en conocimiento de un círculo más amplio de estudiosos. Estoy convencida que estas dos estimulantes Exposiciones sobre los Hernandos, la valenciana y la florentina, darán un nuevo impulso a los estudios de los profundos vínculos culturales que, desde siempre, han unido Italia y España.

${ }^{23}$ Angulo Íñiguez, D.: Pinturas del s. XVI en Toledo y Cuenca. Pedro de Aponte en Atri, en «Archivo Español de Arte», 113, 1956, pp. 43-58; 51-54. En fecha reciente se ha publicado un trabajo muy documentado sobre Pedro de Aponte, donde se discrepa acerca de la autoría de este pintor en las tablas de Atri, véase Morte García, C.: «Los Maestros del retablo», en El Retablo de San Miguel de Agreda (Soria). Historia y Restauración, Soria, 1997, pp. 37-109; esta distinta propuesta ya fue defendida por la misma autora en un trabajo de 1978 y en el que, también adoptó el nombre de Maestro de Bolea, para el principal pintor del retablo mayor de Bolea.

${ }_{24}$ Condorelli, A.: Problemi di pintura valenzana, en «Commentari», XVII, 1966, pp. 112-128. 